NASA Technical Memorandum 105170

$1 N-20$

AIAA-91-2110

$368=4$

$\sqrt{10}$

\title{
Pressure Measurements in a Low- Density Nozzle Plume for Code Verification
}

Paul F. Penko

Lewis Research Center

Cleveland, Ohio

Iain D. Boyd

Eloret Institute

Ames Research Center

Moffett Field, California

and

Dana L. Meissner and Kenneth J. DeWitt

University of Toledo

Toledo, Ohio

Prepared for the

27th Joint Propulsion Conference

cosponsored by AIAA, SAE, ASME, and ASEE

Sacramento, California, June 24-27, 1991

\section{N/Sก}




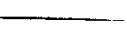




\title{
Pressure Measurements in a Low-Density Nozzle Plume for Code Verification
}

\author{
Paul F. Penko* \\ National Aeronautics and Space Administration \\ Lewis Research Center \\ Cleveland, Ohio 44135 \\ lain D. Boyd** \\ Eloret Institute \\ NASA Ames Research Center \\ Moffett Field, California 94035 \\ Dana L. Meissner and Kenneth J. DeWitt
University of Toledo
Toledo, Ohio 43606
}

Abstract

Measurements of Pitot pressure were made in the exit plane and plume of a lowdensity, nitrogen nozzle flow. Two numerical computer codes were used to analyze the flow, including one based on continuum theory using the explicit MacCormack method, and the other on kinetic theory using the method of direct-simulation Monte Carlo (DSMC). The continuum analysis was carried to the nozzle exit plane and the results were compared to the measurements. The DSMC analysis was extended into the plume of the nozzle flow and the results were compared with measurements at the exit plane and axial stations 12 , 24 and $36 \mathrm{~mm}$ into the near-field plume. Two experimental apparatus were used that differed in design and gave slightly different profiles of pressure measurements. The DSMC method compared well with the measurements from each apparatus at all axial stations and provided a more accurate prediction of the flow than the continuum method, verifying the validity of DSMC for such calculations.

\section{Introduction}

NASA has a continuing effort in developing small rockets that operate on electric power for both primary and auxiliary propulsion on satellites. These rockets are typified by thrusts of order $1 \mathrm{~N}$ or less and also by viscous nozzle flows because of their small size and somewhat high operating temper-

\footnotetext{
- Aerospace Engineer, Member AlAA

* Research Scientisi, Member AlAA

- Graduate Student

- Prot. Chemical Engineering
}

atures. An important consideration in placing such thrusters on a satellite is the effect that the plumes may have on satellite surfaces and systems. Given the viscous nature of the flow, the plumes tend to spread widely in vacuum with a considerable flow in the backward direction. Some major effects from the plume could include contamination from mass deposition and unsatisfactory disturbance torques or thermal loading from impingement on various satellite surfaces.

To gain a better understanding of thrustersatellite interaction and design considerations in placing electric propulsion on satellites, a study of thruster plumes is currently in progress. Assessment of plume effects from small thrusters is being approached analytically by modeling the nozzle flow and plume on the molecular level. Laboratory tests are also being conducted in a vacuum facility to complement the analyses by providing experimental measurements for verification of the numerical codes. Under study are lowdensity, viscous nozzle flows and the plumes that these flows generate in a vacuum. The flows are characteristic of low-thrust devices such as arcjets and resistojets. Of particular interest is the prediction of plume expansion. especially in the off-axis region, that may affect surfaces in the proximity of a thruster.

In a previous study, the flow of carbon dioxide in a nozzle was computed with two numerical techniques predicated on different flow regimes'. The first technique was based on continuum theory and numerically solved 
the Navier-Stokes equations for compressible flow. The second technique was based on kinetic theory and used the method of direct simulation Monte Carlo (DSMC). Both numerical methods were applied to a reference problem defined to be a low-density, viscous gas flow in a convergent-divergent nozzle of conical shape.

The work described in Reference 1 demonstrated that the numerically intensive DSMC technique could be readily applied to a lowdensity nozzle flow, where the flow varied from continuum $\left(K n \sim 10^{-3}\right)$ at the throat to rarefied $\left(K n \sim 10^{-1}\right)$ at the exit plane, where $\mathrm{Kn}$ is the Knudsen number based on local nozzle diameter. The solutions from the two techniques exhibited differences, mainly in the region near the wall at the nozzle lip. In a subsequent study ${ }^{2}$, nitrogen was used in place of carbon dioxide to remove the ambiguity of specifying an effective specific heat ratio in the continuum method, and allowed for a more direct comparison between the analytical schemes.

To provide verification of the analyses, the reference problem was also run as an experiment in a large vacuum facility. The objective of the experiment was to measure pressure in the nozzle exit plane and near-field plume with Pitot tubes. Similar work was done by Bailey and Price ${ }^{3}$ for flow of $\mathrm{CO}_{2}$, and served as a guide for the work of this study. This paper presents pressure measurements taken in a nitrogen nozzle plume and the comparable pressures computed from the two numerical codes.

\section{Reference Problem}

The reference problem was defined to typify the nozzle flow of an electric propulsion device while also matching the flow capacity of the vacuum pumps on the experimental facility. A conical nozzle geometry was selected for both analytical and machining simplicity, but it is also typical of small thruster nozzles. The geometry for the problem is illustrated in Figure 1, with details given in Table 1 . The nozzle operating parameters are listed in Table 2 for two configurations corresponding to two different experimental apparatus and two operating conditions.

The nominal Reynolds Number of 850 , based on throat diameter and stagnation viscosity, is characteristic of a high- temperature, high-performance resistojet" The nozzle was made sufficiently large to minimize probe size relative to the exit diameter and does not resemble actual thruster hardware. Nitrogen was selected as the test gas for analytical convenience and, similarily does not particularly represent an actual working fluid of a spacecraft propulsion system.

\section{Test Facility}

The experimental tests for this study were conducted in a space-simulation vacuum tank. The test apparatus was mounted in a $1 \mathrm{~m} \mathrm{di}$ ameter section about $1 \mathrm{~m}$ in length, and attached to a larger tank $4.9 \mathrm{~m}$ in diameter and $19 \mathrm{~m}$ long. The facility pumping system consists of twenty oil-diffusion pumps in series with four blowers and four roughing pumps. A detailed description of the test facility can be found in Reference 5 .

The pumping system was able to maintain a vacuum during the tests of order $10^{-2} \mathrm{~Pa}$ for a nozzle flowrate of $6.8 \times 10^{-5} \mathrm{~kg} / \mathrm{s}$. The vacuum pressure was monitored with a hotcathode ionization gage mounted on the test section and connected to a digital meter

\section{Experimental Apparatus}

The test apparatus consisted of a heat exchanger and nozzle that simulated a thruster and traversing tables that permitted surveying the plume with pressure probes. Two heat-exchanger assemblies of different design were used in the tests. The purpose of the second design was to reduce the temperature of the heating element to lengthen its operational life.

In the original apparatus (configuration 1), the nitrogen was heated in a $3.2 \mathrm{~mm}$ diameter tube that was coiled around a $15.9 \mathrm{~mm}$ cartridge heater. In the newer apparatus (configuration 2), the nitrogen was heated in an annular area comprised of a $12.7 \mathrm{~mm}$ diameter cartridge heater contained in a larger tube of $17.3 \mathrm{~mm}$ internal diameter. A schematic of this configuration is shown in Figure 2. The heater for configuration 2 had a lower power density than configuration 1. The heat exchangers produced the same gas temperature, but the second design lowered the heat conduction along the heat-exchanger and nozzle walls and produced nozzle wall tem- 
peratures about $40^{\circ} \mathrm{K}$ lower. Nozzle wall temperatures for each configuration are listed in Table 2.

Although the nozzles for each configuration were machined from the same specifications, the chamber pressures were slightly different for equivalent flowrates and gas temperatures as listed in Table 2. Configuration 1 had a chamber pressure of $6400 \mathrm{~Pa}$ which was slightly higher than the $6210 \mathrm{~Pa}$ of configuration 2. The difference in chamber pressures implied a difference in the throat diameters of about $1 \%$ where the nozzle of configuration 2 was the larger of the two

In both cases, the pressure and temperature of the flow were measured upstream of the nozzle in a $22 \mathrm{~mm}$ diameter plenum. The measurements were effectively nozzle-inlet stagnation conditions as the ratio of area at the measurement station to the throat area was about 48:1. The pressure was measured with a capacitance manometer having a range of 0 to $13.3 \mathrm{kPa}$. Temperature was measured with a half-shielded, chromel-alumel thermocouple located at the centerline of the measurement station, and connected to a digital voltmeter with self-contained, coldjunction compensation. Flow of the nitrogen was measured with a transducer that relates thermal changes in a capillary tube to volumetric flowrate A schematic of the flow system is shown in Figure 3.

The test apparatus was specifically designed for making measurements in an expanding flow by use of a traversing mechanism. The mechanism consisted of a rotary table mounted atop two linear tables which provided freedom in the radial, axial and rotational directions. The range of travel was $24 \mathrm{~mm}$ in the radial direction (R), $36 \mathrm{~mm}$ in the axial direction $(Z)$, and $360^{\circ}$ in rotation $(\theta)$. The tables were manually positioned through mechanical links between the rotary handles on each table and handles outside the vacuum chamber. Each traverse position was monitored by a linear-variable-differential transformer (LVDT) mounted on each of the linear tables, and a rotary LVDT on the rotary table. LVDT output signals were read on a digital voltmeter.

A Pitot tube of $1.0 \mathrm{~mm}$ outside diameter and $0.15 \mathrm{~mm}$ wall thickness was used to measure pressure and flow angle in the nozzle exit plane and plume. The probe had a $30^{\circ}$ chamfer on the internal diameter at the tip to form a sharp lip at the leading edge. The ube was bent in a U-shape so that the tip was located on the axis of rotation of the rotary table as shown schematically in Figure 2. The Pitot tube was attached directly to a capacitance manometer having a range of 0 to $1.33 \mathrm{kPa}$, and accuracy of $0.1 \%$ of full scale, to measure the pressure.

Nozzle wall temperatures were measured by two chromel-alumel thermocouples tackwelded to the outer wall surface. One thermocouple was located about mid-way beween the nozzle throat and exit plane $\left(T_{w 1}\right)$, and the other, at the exit plane $\left(T_{m}\right)$, as shown in Figure 1.

\section{Test Procedure}

The test section containing the expermental apparatus was first evacuated, without flow, and the capacitance manometers zeroed. The vacuum pressure without flow was about $10^{-4} \mathrm{~Pa}$ which served as the zeroreference pressure for the manometers. The nowmeter was zeroed while containing nitrogen at the accumulator supply pressure. After all instrumentation was zeroed, flow was established at $6.8 \times 10^{-5} \mathrm{~kg} / \mathrm{s}$ and maintained by the flow controller. Simultaneously, 70 volts at about $0.9 \mathrm{~A}$ was applied to the cartridge heater and time allowed for the system to equilibrate at a nozzle inlet temperature of 700 K.

After the system reached steady-state, pressure scans were made by moving the Pitot tube to a given axial and radial location and then rotating the probe to determine the point of maximum pressure. The maximum pressure was the Pitot pressure reading for the particular location and the rotation angle, $\theta$, was the flow-angle reading. A typical rotary scan, in this case at the exit plane $(Z=0 \mathrm{~mm})$ and a radial position $12 \mathrm{~mm}$ from the nozzle centerline, is shown in Figure 4 . The flow angles were measured with respect to the nozzle axis The error in the pressure measurement was estimated to be $\pm 5 \mathrm{~Pa}$, and in the flow angle, $\pm 2^{\circ}$.

Pressure scans were made primarily in the horizontal plane of the apparatus. Comparisons of vertical and horizontal scans of pressure across the entire nozzle diameter indicated that the flow was symmetrical, within experimenal error. All reported pres- 
sure scans were taken only in the horizontal plane starting at the nozzle centerline $(R=0)$

\section{Analytical Methods}

Two methods of analysis were applied to the problem. One was a numerical code based on continuum flow, and the other, a code based on kinetic theory that considered molecular motion by the method of directsimulation Monte Carlo.

\section{Continuum Method}

The continuum computation of the flow was made with the numerical code termed the Viscous Nozzle Analysis Program, version 2 (VNAP2) $^{6}$. The code solves the Navier-Stokes equations for a compressible fluid in timedependent, non-conservative form by the explicit, two-step MacCormack method which gives second-order accuracy in space. With this scheme the equations are marched in time from a specified initial flowfield to a steady-state solution. For this problem, given the relatively low Reynolds number, laminar flow was assumed. Also assumed was an adiabatic nozzle wall.

The code produces a body-fitted, nonorthogonal grid in physical coordinates that, by transformation, is rectangular in computational space. For the problem in this study, 31 radial and 51 axial grid lines were specified. Furthermore, the grid was clustered in the nozzle throat and near the nozzle wall to capture adequately the steep gradients of the flow variables in those regions.

The computation was started in the upstream, subsonic portion of the nozzle. The inflow conditions included total pressure and temperature, and zero radial velocity. The subsonic inflow boundary employed the method of characteristics such that the axial velocity and static pressure and temperature were determined from interior, downstream points, and evolved with the solution from initial values.

Since the stream exhausted to an ambient pressure near zero, the outflow boundary condition for the subsonic portion of the flow in the exit plane was modified from the original scheme which required the explicit specification of an ambient pressure. It was assumed that the pressure of the subsonic flow did not match the ambient at the exit plane and was not known a priori, but did match the ambient at some finite distance into the plume. This condition was simulated by extrapolating the exit-plane pressure from interior points (as normally done in the supersonic flow) in the subsonic region at each time step and along each grid line, then using the new value as the specified ambient pressure. In this manner the exit-plane pressure was continually updated iteratively. This scheme computed relatively smooth profiles of properties in the vicinity of the wall at the exit plane, but did impose an effective back pressure on the flow. In cases where the subsonic exit-plane pressure was explicitly fixed, the properties exhibited a discontinuity across the sonic line where the flow decelerates from supersonic to subsonic in the direction normal to the wall.

The scheme was marched for 20,000 timesteps from an initial condition corresponding to one-dimensional, isentropic flow. The solution required about $0.8 \mathrm{~h}$ of CPU time on a Cray-YMP. Convergence of the scheme was not monitored as such but conservation of mass was checked and used as a guide. At 20,000 timesteps the mass flow was fairly consistent throughout the nozzle. In the diverging section it was within $1 \%$ of the value specified by the inlet conditions, and in the converging section, within $2 \%$.

\section{Monte Carlo Method}

The Monte Carlo method used to simulate the nozzle now was developed by Boyd ${ }^{7}$ after the method of Birds. The code was highly optimized and specifically structured for vectorization on a supercomputer, and permitted the practical use of a large number of simulated molecules and computational cells necessary to model an internal flow.

Particle collisions were simulated in the code by the Variable Hard Sphere model of Bird". The number of collision pairs sampled in each cell is based on a probability function dependent on particle relative velocity and collision cross-section. Rotational nonequilibrium was included in the scheme with a relationship developed by Boyd for the probability of energy transfer between the translational and rotational modes and was fully integrated into the vectorized procedures of the code. 
The No-Time-Counter method of Bird ${ }^{10}$ was employed for the collision algorithm. In this method, all simulation molecules are available as collision partners and adapted well to vectorization in computing post-collision properties. The algorithm that traces particle motion uses a scheme of nonregular cells, where the four line segments that define a computational cell are stored, and each particle located with respect to the lines of the cell. In this manner the cell index of algebraic expression

is evaluated by a simple alse adapted well to vectorization

The nozzle flow was modeled in axisymmetric coordinates and started at the point downstream of the throat where the conical section began. The grid for the computations was derived from the continuum solution and cell dimensions were set to be no greater than two local mean-free paths throughout the flow domain. The entire nozzle flow including a portion of the plume was spanned with 38,000 computational cells. As the number density ranged over two orders of magnitude in the expanding flow, cell dimensions and the timestep were varied on a local basis. Along the nozzle wall, a fully accommodated, diffusely-reflecting boundary condition was applied using the profile of wall temperature obtained from the continuum solution scaled by the thermocouple measurements. The initial inflow condition of macroscopic properties at the nozzle throat was also obtained from the continuum solution.

The simulation was configured such that the computational domain held about 1.7 million particles at the point of steady state. The code performed the necessary movements and collisions of the particles at the rate of 2000 timesteps and 400 million collisions per CPU hour. The execution speed, measured in CPU time/particle/timestep, was $1.1 \mu \mathrm{s}$ on a Cray-YMP. The transitory stage of the computation took about 10,000 timesteps before sampling of microscopic quantities could reasonably begin because of local decoupling of the timestep and molecules entering the inflow surface at sonic speed only. The solution required a total of 3 $h$ of CPU time to reach steady state and march through 1800 timesteps of averaging of the microscopic quantities. A more detailed description of the method may be found in References 1 and 2 .

\section{Comparison of Numerical Results}

The computed flowfield for the nozzle problem from both numerical schemes is shown in Figure 5, where contours of constant Mach number are plotted. The results from the continuum computation are shown in the upper half and those from the DSMC computation in the bottom half. The continuum results end at the nozzle exit plane and the DSMC results extend into the plume. The vertical line in the lower half of the plot indicates the plane where the computed data from the DSMC calculations were terminated because of the amount of statistical scatter exhibited by the data in the back-flow region, which is to the left of the line.

The Mach contours clearly illustrate the viscous nature of the flow, and also illustrate differences in the computed results from the numerical schemes. In the region immediately downstream of the throat, the results from each numerical scheme are similar as would be expected since the DSMC method used the flow profiles from the continuum method for the inflow surface and the flow is most probably in thermal equilibrium given the low Knudsen number. The results begin to differ downstream of the inflow surface and differ considerably at the exit plane of the nozzle. The most notable difference is near the exit plane where the sonic line in the DSMC solution curves toward the wall and intersects the nozzle lip as the flow suddenly expands into the vacuum.

The DSMC model clearly allows greater expansion of the flow inside the nozzle because the flow is not restricted by a back pressure as is the case with the continuum model. As previously mentioned, a finite back pressure is effectively applied in the continuum computation by way of the outflow boundary condition. By comparison, the outflow boundary in the DSMC method is essentially absolute vacuum. Furthermore, the boundary condition for the wall in the continuum code specifies non-slip of the velocity. In the DSMC method velocity slip at the wall is inherent. Consequently, the two solutions are not directly comparable. The flow in the throat region is not appreciably affected by the outflow boundary condition so the continuum result should have provided a credible inflow starting condition for the DSMC model. 


\section{Calculation of Pitot Pressure}

To compare the numerical solutions with experimental data, Pitot pressures were first calculated from the numerical results using the computed state variables. The calculated Pitot pressure can be viewed as the pressure that would be measured if a Pitot tube were inserted into the stream computed by the numerical codes. Since the flow was both supersonic and rarefied, the calculation involved a two-step process:

1. The pressure ratio across a normal shock was calculated with the Rayleigh Pitot tube equation (c.f. Ref. 11, p. 154) represented by

$$
P_{o y} / P_{x}=f\left(y, M_{x}^{2}\right)
$$

where $P_{o y}$ is the total pressure behind the shock, $P_{x}$ and $M_{x}$ are the static pressure and Mach number ahead of the shock obtained from the numerical solutions, and $\gamma=1.4$ is the ratio of specific heats.

2. The ideal pressure $P_{\text {oy }}$ was corrected for rarefaction effects by

$$
\begin{gathered}
\log \left(P_{\text {om }} / P_{\text {oy }}\right)=.089-.120 \log \left(R e_{p}\right) \\
R e_{p} \leq 5.6
\end{gathered}
$$

In equation (2), $R e_{p}$ is the probe Reynolds number and $P_{o m}$ is the corrected total pressure behind the shock and is the pressure that would actually be measured with a Pitot tube Equation (2) is a fit of data obtained from a report on rarefaction effects of Pitot tubes for measuring pressure in rarefied, supersonic, wind-tunnel flow ${ }^{12}$. In Reference 12, the factor $P_{\text {om }} / P_{\text {oy }}$. which is always $\geq 1$, was plotted as a function of $R e_{\rho}$, with total temperature of the stream, $T_{0}$, as parameter. Equation (2) is a fit of the parametric curve for $T_{0}=700 \mathrm{~K}$.

In Reference 12, the probe Reynolds number was defined as

$$
R e_{p}=\rho_{\infty} U_{\infty} D_{\rho} / \mu_{y}
$$

where $\rho_{\infty}$ and $U_{\infty}$ are the density and velocity of the free stream preceding the shock, $D_{p}$ is the probe diameter, and $\mu_{y}$, the viscosity of the gas at the stream temperature, $T_{y}$, behind the shock. In the probe Reynolds number, the actual diameter of the Pitot fube on the experimental apparatus was used for $D_{p}$. The values of $\rho_{\infty}$ and $U_{\infty}$ were obtained directly from the output of the codes, except for the DSMC results, where the mass density was first calculated from number density, the actual quantity computed by the code.
The viscosity, $\mu_{y}$, was derived from the numerical results by first calculating the temperature $T_{y}$. This quantity was computed from the normal-shock relation for static temperature (c.f. Ref. 11, p. 118) represented by

$$
T_{y} / T_{x}=f\left(\gamma, M_{x}{ }^{2}\right)
$$

where the values of static temperature ahead of the shock, $T_{x}$, and the Mach number, $M_{x}$, were obtained from the numerical solutions. The viscosity was then found from the standard temperature power-law relating the viscosity of gases (c.f. Ref. 13, p. 28)

$$
\mu_{y}=\mu_{\text {ref }}\left(T_{y} / T_{\text {ref }}\right)^{n}
$$

where $\mu_{\text {ret }}$ is the value for viscosity of nitrogen $n=0.75$.

The presentation of analytical results from the DSMC solutions (except those of Figure 7) utilize $P_{o m}$. No corrections were made to the Pitot-pressure measurements.

\section{Experimental and Analytical Results}

Radial scans of Pitot pressures for both experimental configurations, at an axial station $12 \mathrm{~mm}$ from the exit plane of the nozzle are shown in Figure 6. The pressures from configuration 2 (triangular symbol) are lower, and the profile flatter, in the core flow near the centerline than those for configuration 1 (circular symbol). The pressures from both configurations are nearly the same in the outer region of the plume. This figure is typical of the difference in pressure profiles between the two experimental configurations.

A comparison of results from the numerical methods and the experimental data at the nozzle exit plane $(Z=0)$ is given in Figure 7 for configuration 1 . Plotted in the figure is Pitot pressure, both measured and calculated from each of the numerical methods, as a function of radial distance. The radial scale starts at the nozzle axis and extends to the nozzle wall at $16 \mathrm{~mm}$. In this figure the results from the numerical methods are not corrected for rarefaction effects, so the numerical results are those for the ideal, total pressure, $P_{\text {oy }}$, behind a normal shock. Because of the fairly large region of subsonic flow in the continuum solution, the correction for rarefaction effects could not be applied to a considerable portion of the flow (a subsonic probe-recovery factor would have to be used). Furthermore, in the 
core region near the centerline where the variation in pressure is greatest between the two analyses, $R e_{\rho}>5.6$, making the rarefaction correction nil. Thus for a fair portion of the flow, Figure 7 presents a valid comparison of the pressures. It can be seen from the figure that the DSMC computation gives the better correspondence to the experimental data. The continuum computation, while yielding a higher pressure in the core, yields a slightly lower pressure in the viscous region near the wall.

In Figure 8, Pitot pressures computed from the DSMC results (all remaining results are corrected for rarefaction effects) and experimental data are given at the axial station 12 $\mathrm{mm}$ from the exit plane for configuration 1 . The profiles of Pitol pressure extend radially from the nozzle centerline to $24 \mathrm{~mm}$. From the figure, the DSMC solution is seen to give good agreement to the experimental measurements.

Similar plots of DSMC results and experimental data for configuration 1 , at axial stations of $24 \mathrm{~mm}$ and $36 \mathrm{~mm}$ from the nozzle exit plane are given in Figures 9 and 10 . In these figures, the radial scan is also from the nozzle centerline to $24 \mathrm{~mm}$. Again, the correspondence is quite good.

Pitot pressures computed from the DSMC results and measured values for configuration 2 are presented in Figures 11 through 14 . The axial stations are, as before, at the exit plane $(Z=0)$ and 12,24 , and $36 \mathrm{~mm}$ downstream into the plume. In general, the DSMC solution reasonably predicts the measured pressure profiles. In Figures 12 and 13 , at the 12 and $24 \mathrm{~mm}$ axial stations, the centerline pressure from the DSMC solution is nearly identical to the measured value. The pressures from the DSMC solution are slightly lower at all radial positions for the $36 \mathrm{~mm}$ axial station, Figure 14.

Finally, Figure 15 shows a comparison of flow angles from the DSMC solution and measured values from configuration 2 for the axial station $12 \mathrm{~mm}$ from the exit plane. There is fair agreement between the computed and measured values of flow angle, with the largest descrepancy occuring at a radial distance of about $10 \mathrm{~mm}$. The experimental measurements exhibited some scatter in the region from $8 \mathrm{~mm}$ to $12 \mathrm{~mm}$ in radial distance.

\section{Discussion of Results}

In general the correspondence between the DSMC results and experimental data is better for configuration 1, but the DSMC solutions do predict the difference in pressure profiles between the two experimental apparatus. As previousiy mentioned, the principal difference in experimental configurations was the design of the heat exchangers. The earlier design (configuration 1) produced nozzle wall temperatures about $40^{\circ} \mathrm{K}$ higher because of higher heat conduction along the tube of the heat exchanger to the nozzle wall. The cooler wall of configuration 2 would tend to flatten the pressure profile as the density and pressure of the flow near the wall would be higher relative to the centerline region. Also, for the same flowrate, the total pressure of $6210 \mathrm{~Pa}$ for the nozzle of configuration 2 was slightly lower than the $6400 \mathrm{~Pa}$ of configuration 1 which would give lower stream pressures overall for configuration 2.

The continuum code was not run for the conditions of configuration 2, so properties of the inflow surface were not provided the DSMC model for this case. Rather, the inflow number density for the DSMC simulation was scaled from the perfect gas relation, where the stream static temperature was the same as the first case. Nozzle surface temperatures were scaled from experimental measurements to simulate the wall boundary condition for configuration 2. Although the DSMC simulation for configuration 2 needs some refinement, the computed results, nonetheless, agree reasonably well with the experimental data.

One factor that would affect the comparison between computed and experimental results is the actual ambient pressure of the test facility. In particular, the facility pressure during testing was about $10^{-2} \mathrm{~Pa}$ whereas an absolute vacuum was essentially assumed for the DSMC simulation. The ambient pressure of the test facility would restrict plume expansion and have an effect on both pressure and flow angle, especially in the far-field regions of the plume. This may be the reason that the pressures from the DSMC simulation were slightly less than measured values at an axial distance of $36 \mathrm{~mm}$ as given in Figure 14 . 


\section{Summary and Conclusion}

A nozzle flow typical of small thrusters used on satellites was simulated by an experimental apparatus and Pitot pressures measured in the exit plane of the nozzle and at three axial stations downstream of the exit plane. The measurements were made on two experimental apparatus differing in heatexchanger design and corresponding to two slightly different operating conditions. The measurements were made to specifically validate computed results from a kinetic theory model of the flow using the DSMC technique. The measurements were also used to check results from a continuum model, although the continuum model was used primarily to specify an inflow surface and aid in defining a grid for the DSMC model. Comparisons were made between the measured pressures and the equivalent pressure derived from the numerical results, including a correction for rarefaction effects

Design differences in the laboratory apparatus resulted in differences in the measured profiles of Pitot pressure that were corroborated by the DSMC method when the appropriate pressure and wall temperatures were used in the simulation. Agreement between the experimental measurements and the DSMC results was quite good which verifies the validity of the method for computing lowdensity nozzle and plume flows. The comparisons emphasize the importance of having experimental data available from a laboratory apparatus for validating a numerical simulation.

\section{References}

1. Boyd, I.D., Penko, P.F., and Carney, L.M., "Efficient Monte Carlo Simulation of Rarefied Flow in a Small Nozzle," AIAA Paper 90-1693, June 1990.

2. Boyd, I.D., Penko, P.F., and Meissner, D.L., "Numerical and Experimental Investigations of Nozzle and Plume Flows of Nitrogen," AlAA Paper 91-1363, June, 1991.

3. Bailey, A.B., and Price, L.L., "Flow Field
Mapping of Carbon Dioxide Nozzle Expansion into Vacuum," AEDC-TR-85-26, July 1985.

4. Yoshida, R.Y., Halbach, C.R., and Hill, S.C., "Life Test Summary and High Vacuum Tests of 10 mlb Resistojets," J. Spacecraft and Rockets, Vol. 8, No. 4, pp. 414-416, April 1971.

5. Finke, R.C., Holmes, A.D. and Keller, T.A., "Space Environment Facility for Electric Propulsion Systems Research," NASA TN-D-2774, 1965.

6. Cline, M.C., "VNAP2: A Program for Computation of Two-Dimensional, TimeDependent Compressible, Viscous Internal Flow," Los Alamos Laboratory Report LA-7326, Nov. 1978.

7. Boyd, I.D., "Vectorization of a Monte Carlo Method For Nonequilibrium Gas Dynamics," $J$. of Computational Physics (to be published).

8. Bird, G.A., "Monte Carlo Simulation in an Engineering Context," in Rarefied Gas Dynamics, edited by Sam S. Fisher, Vol. 74 of Progress in Astronautics and Aeronautics, Part 1, AIAA, New York, 1931, pp. 239-255.

9. Boyd, 1.D., "Analysis of Rotational Nonequilibrium in Standing Shock Waves of Nitrogen," AIAA Journal, Vol. 28, No. 11, Nov. 1990, pp. 1997-1999.

10. Bird, G.A., "Perception of Numerical Methods in Rarefied Gasdynamics," in Rarefied Gas Dynamics, edited by E.P. Muntz, D. Weaver, and D.H. Campbell, Vol. 118 of Progress in Astronautics and Aeronautics, AIAA, Washington, 1989, pp. 211-226.

11. Shapiro, A.H., The Dynamics and Thermodynamics of Compressible Fluid Flow, The Ronald Press Co., New York, 1953

12. Stephenson, W.B., "Use of the Pitot Tube in Very Low Density Flows," AEDC-TR-81-11, Oct. 1981.

13. White, F.M., Viscous Fluid Flow, McGraw-Hill, Inc., New York, 1974. 
Table 1. Nozzlc Gcometry

\begin{tabular}{ll}
\hline Throat diameter, $D_{\mathfrak{l}}$ & $3.18 \mathrm{~mm}$ \\
Exil diameter, $D_{e}$ & $31.8 \mathrm{~mm}$ \\
Inlel diameter, $D_{i}$ & $22.1 \mathrm{~mm}$ \\
Wall thickness, $t_{w}$ & $1.65 \mathrm{~mm}$ \\
Area ratio, $\left(D_{e} / D_{\mathfrak{l}}\right)^{2}$ & 100 \\
Inlet half-angle, $\theta_{i}$ & $45^{\circ}$ \\
Exit half-angle, $\theta_{e}$ & $20^{\circ}$
\end{tabular}

Table 2. Nozzle Flow Conditions for the Two Experimental Configurations

\begin{tabular}{lcc}
\hline Configuration & 1 & 2 \\
\hline Total pressure, $\mathrm{P}_{\mathrm{o}}$ & $6400 \mathrm{~Pa}$ & $6210 \mathrm{~Pa}$ \\
Total temperature, $\mathrm{T}_{\mathrm{O}}$ & $699 \mathrm{~K}$ & $700 \mathrm{~K}$ \\
Mass flow, $\dot{\mathrm{m}}$ & $6.8 \times 10^{-5} \mathrm{~kg} / \mathrm{s}$ & $6.8 \times 10^{-5} \mathrm{~kg} / \mathrm{s}$ \\
Reynolds number, Re* & 850 & 850 \\
Wall temperature, $\mathrm{T}_{\mathrm{w} 1}$ & $551 \mathrm{~K}$ & $507 \mathrm{~K}$ \\
Wall temperature, $\mathrm{T}_{\mathrm{w} 2}$ & $539 \mathrm{~K}$ & $498 \mathrm{~K}$ \\
\hline
\end{tabular}

* $R e=4 \dot{m} / D_{t} \mu_{0}$, where $\mu_{0}$ is the gas viscosity at $T_{0}$

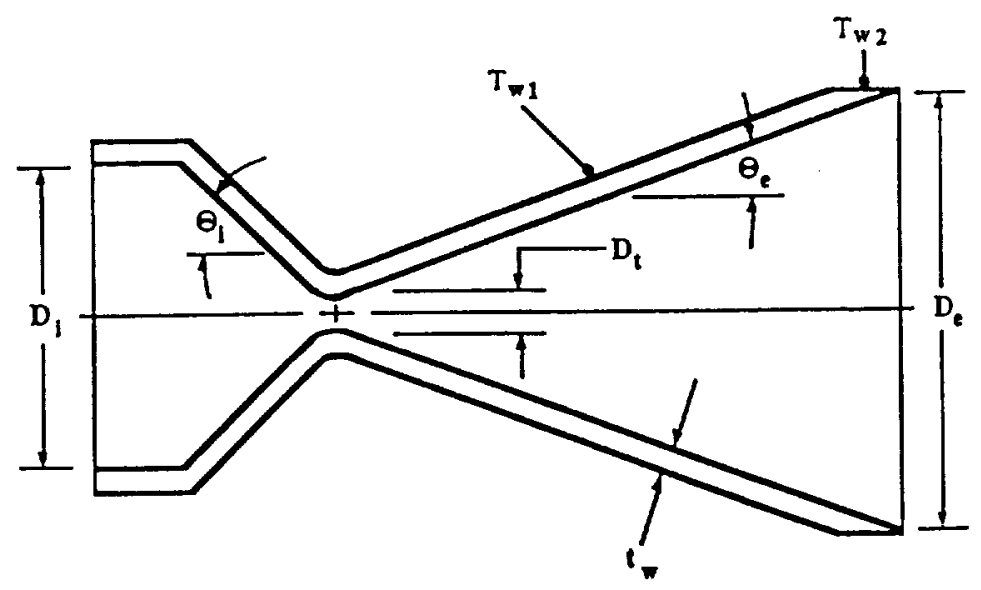

Figure 1. Nozzle Diagram 


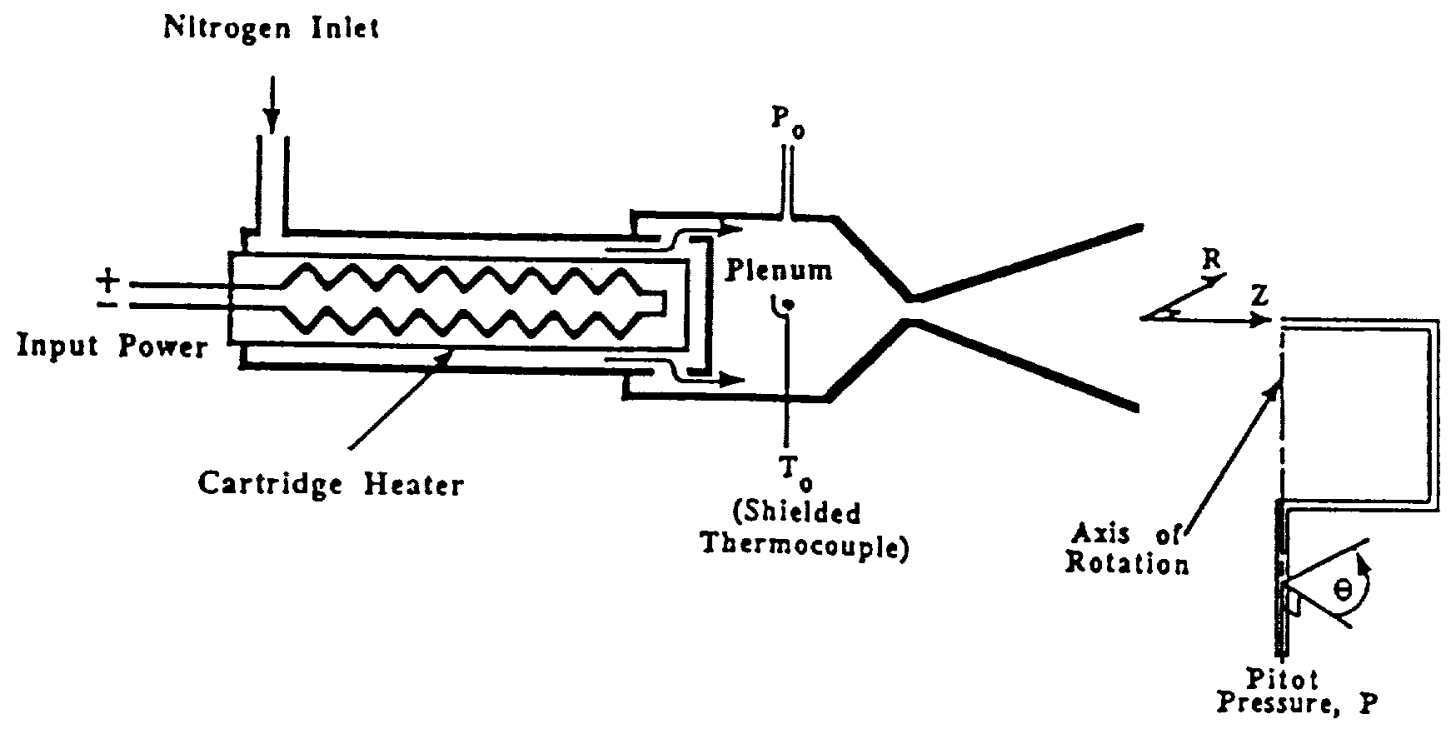

Figure 2. Schematic of Simulated Thruster

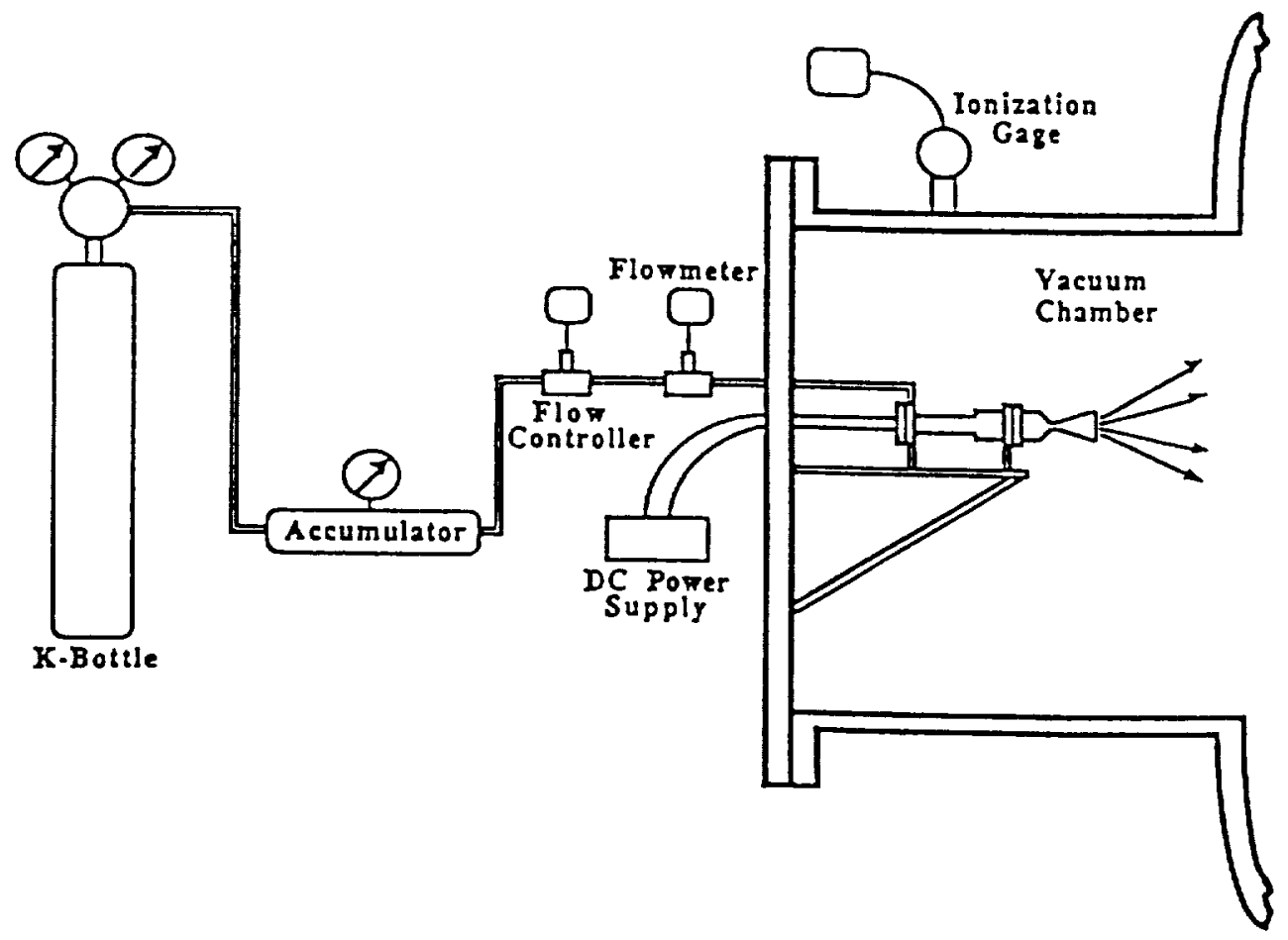

Figure 3. Schematic of Experimental Apparatus 


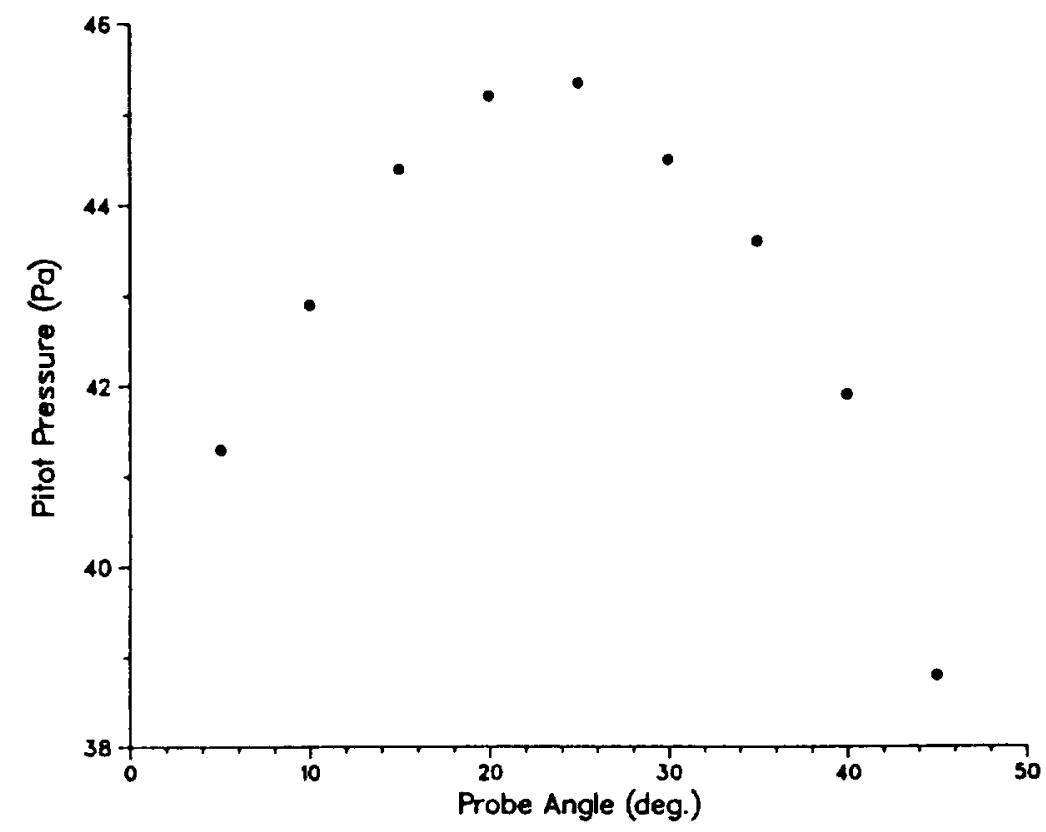

Figure 4. Measured Pitot Pressure versus Probe Angle (Axial Location, $Z=0 \mathrm{~mm}$ and Radial Location, $R=12 \mathrm{~mm}$ )

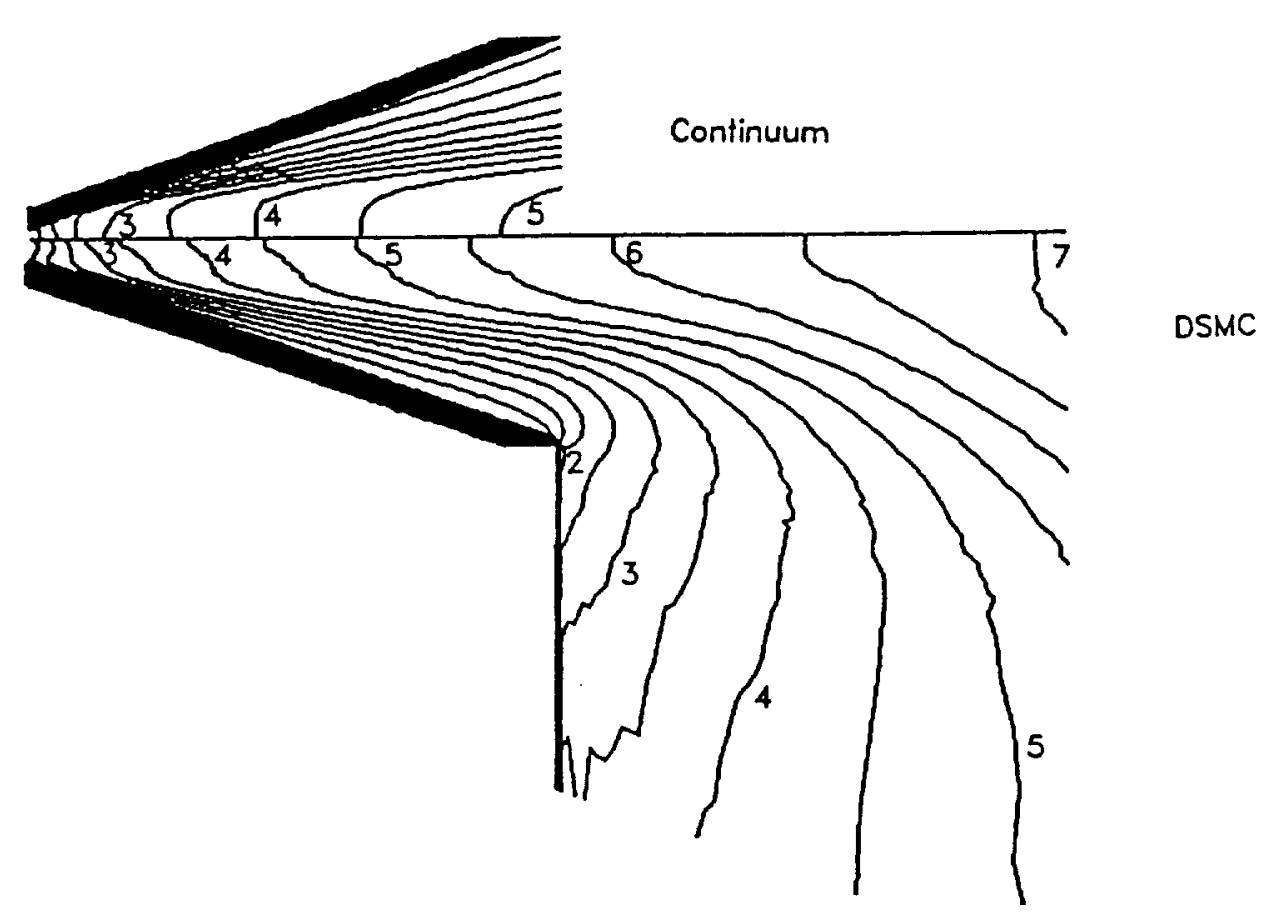

Figure 5. Computed Contours of Mach Number from the Continuum and DSMC Analyses 


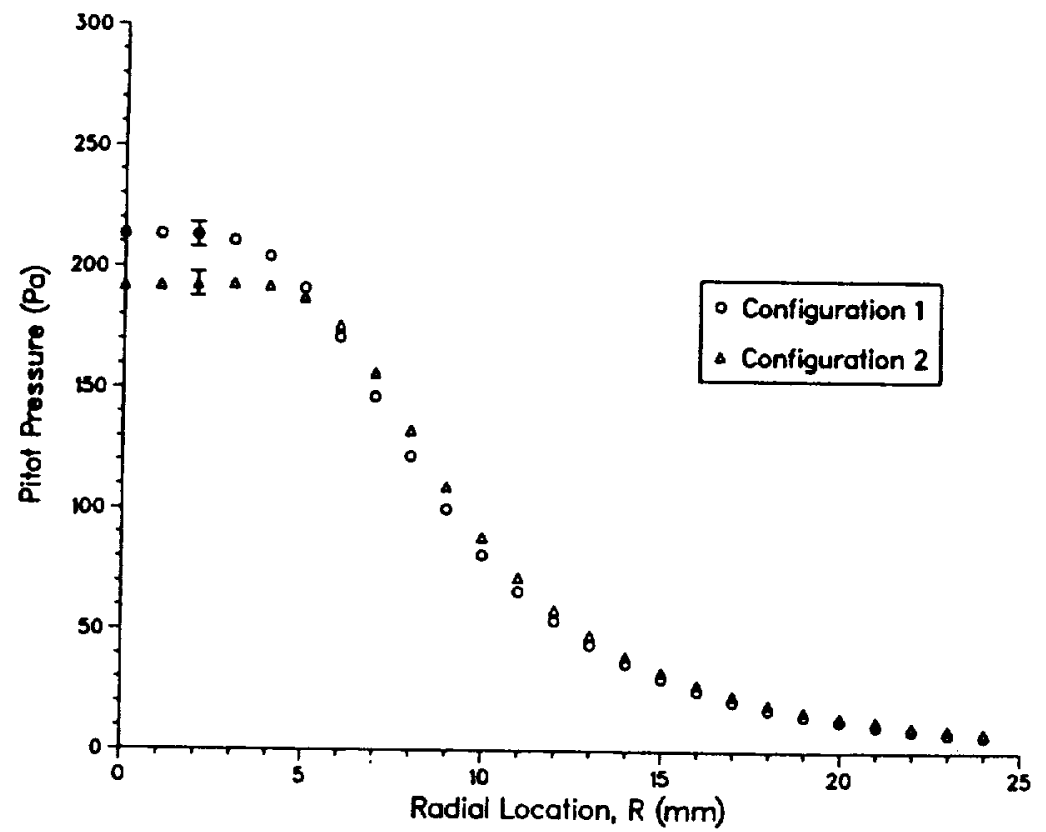

Figure 6. Measured Pitot Pressure Profiles for Configuration 1 and 2 (Axial Location, $Z=12 \mathrm{~mm}$ )

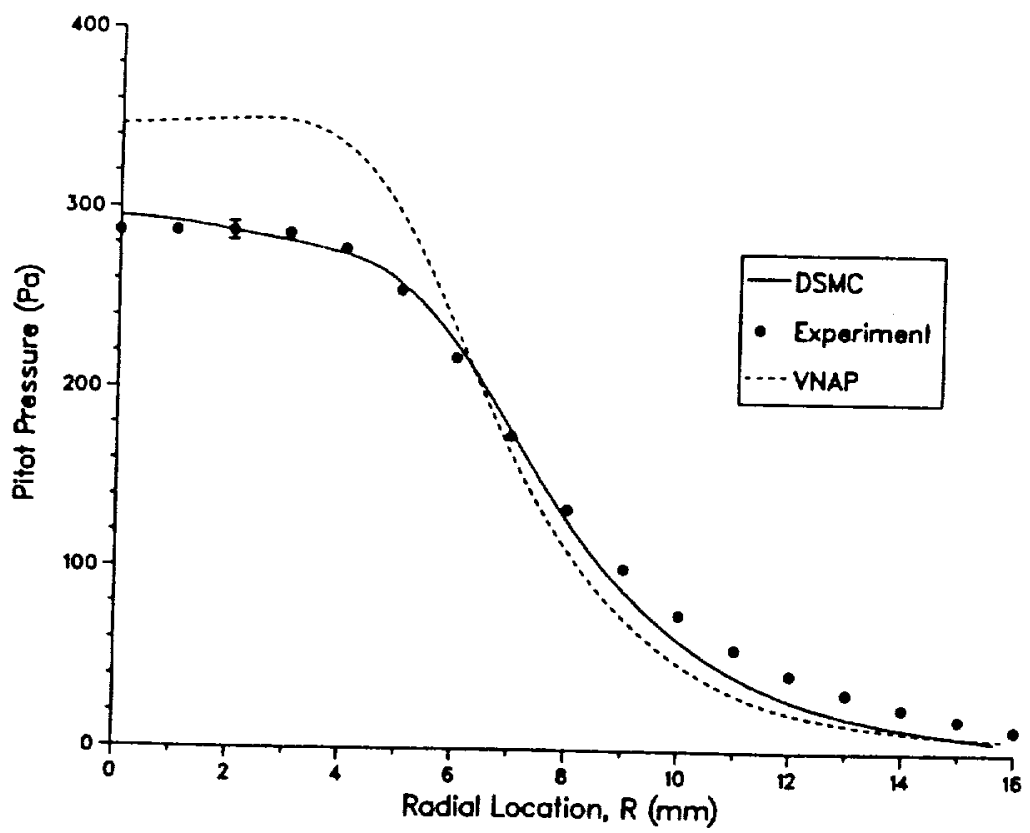

Figure 7. Comparison of Pitot Pressure Profiles for Configuration 1 (Axial Location, $\mathrm{Z}=0 \mathrm{~mm}$ ) 


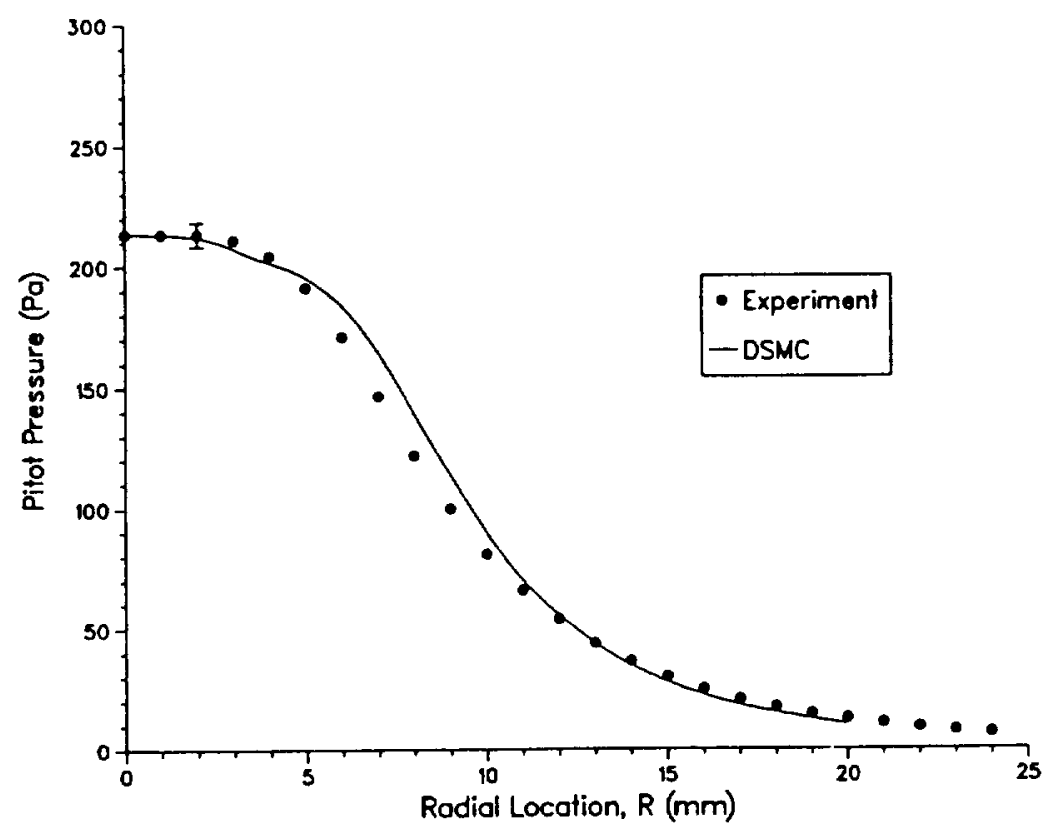

Figure 8. Measured and DSMC Pitot Pressure Profiles for Configuration 1 (Axial Location, $Z=12 \mathrm{~mm}$ )

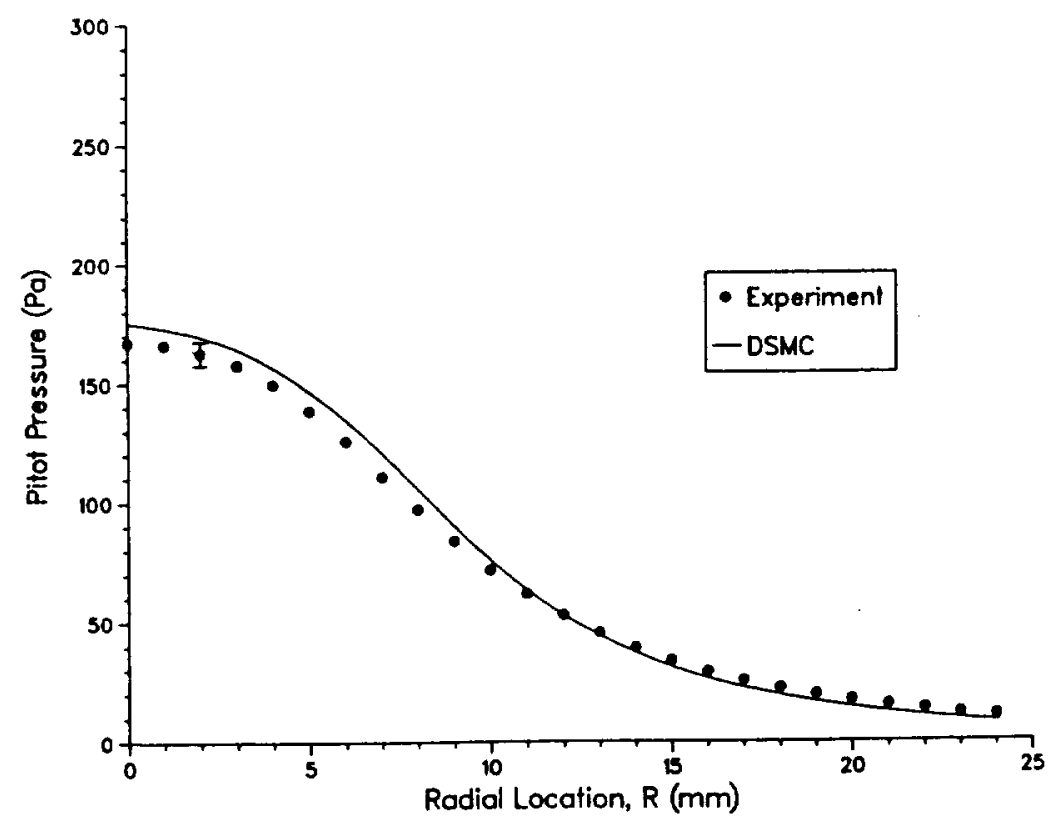

Figure 9. Measured and DSMC Pitot Pressure Profiles for Configuration 1 (Axial Location. $Z=24 \mathrm{~mm}$ ) 


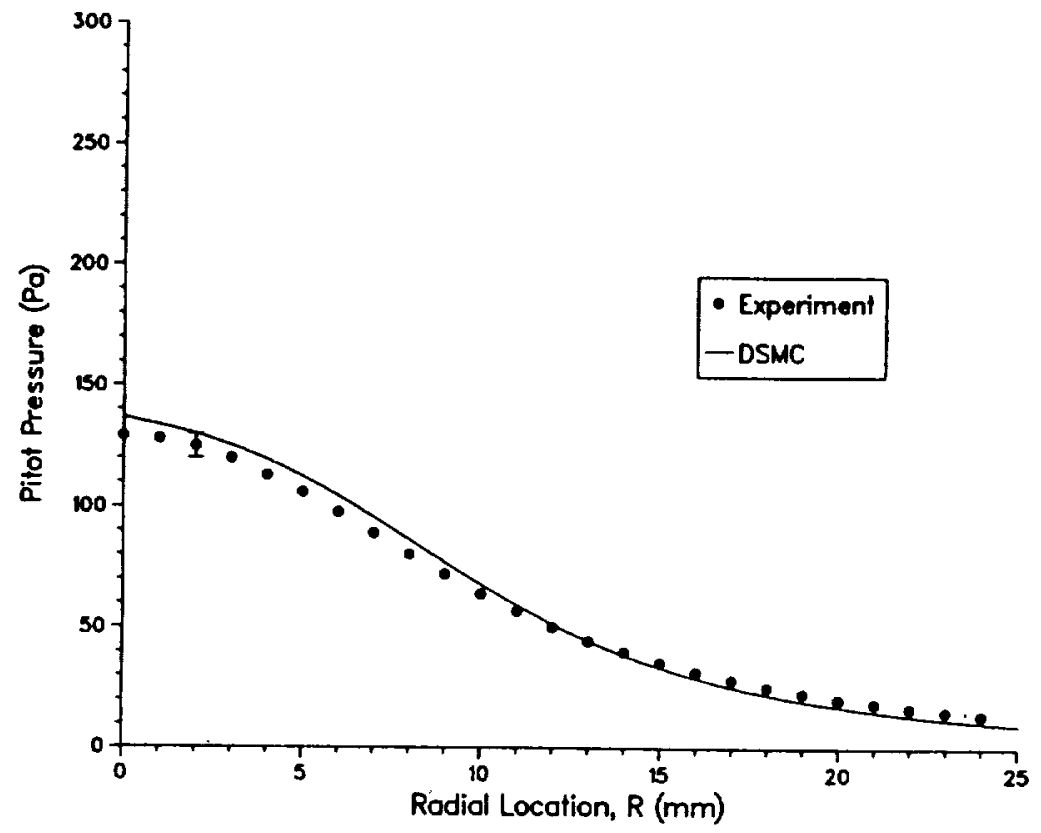

Figure 10. Measured and DSMC Pitot Pressure Profiles for Configuration 1 (Axial Location, $Z=36 \mathrm{~mm}$ )

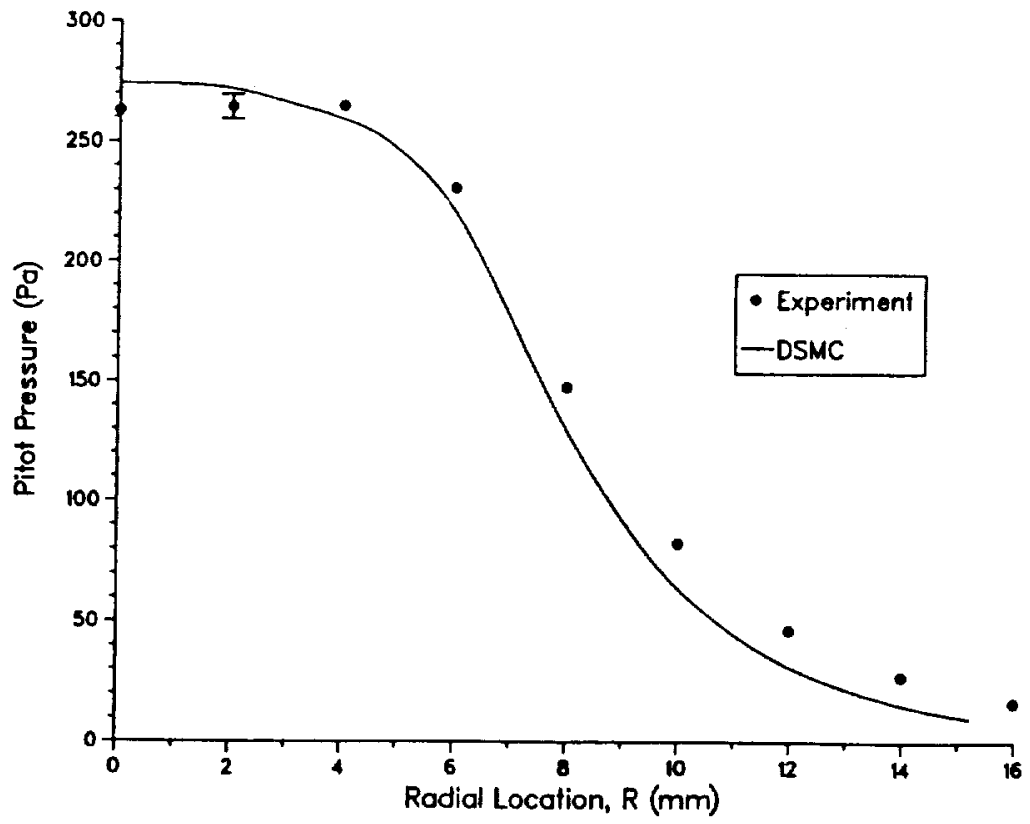

Figure 11. Measured and DSMC Pitot Pressure Profiles for Configuration 2 (Axial Location, $Z=0 \mathrm{~mm}$ ) 


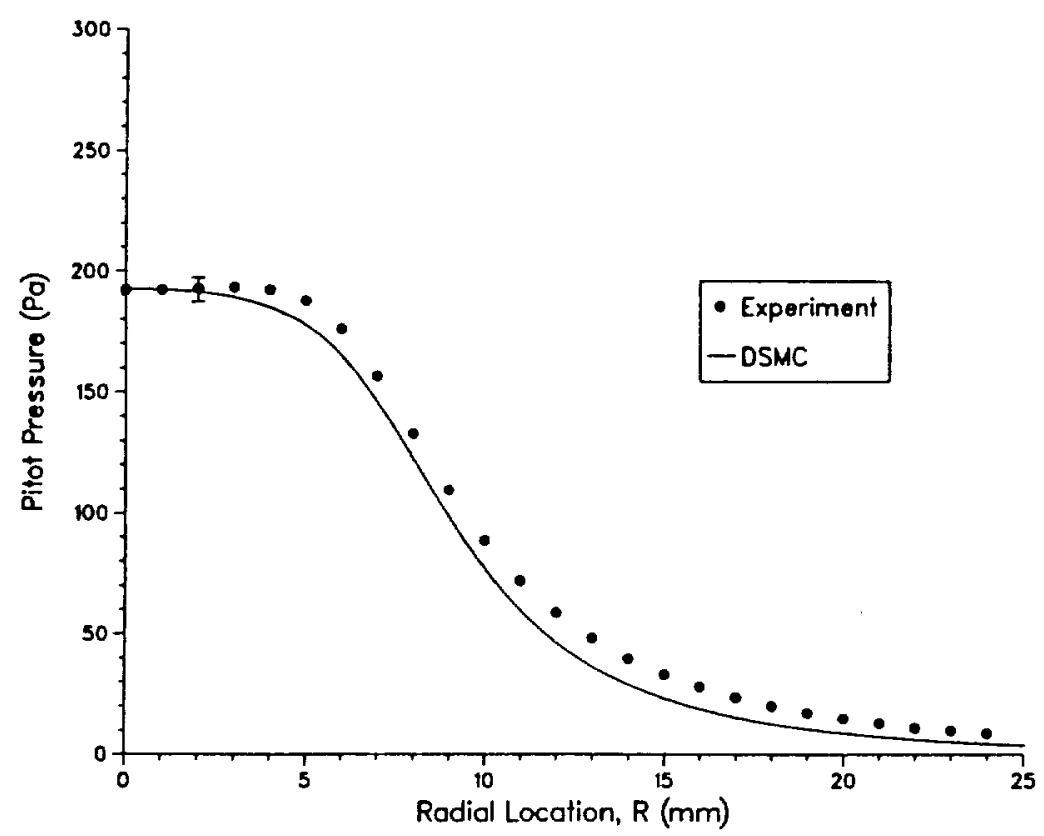

Figure 12. Measured and DSMC Pitot Pressure Profiles for Configuration 2 (Axial Location, $Z=12 \mathrm{~mm}$ )

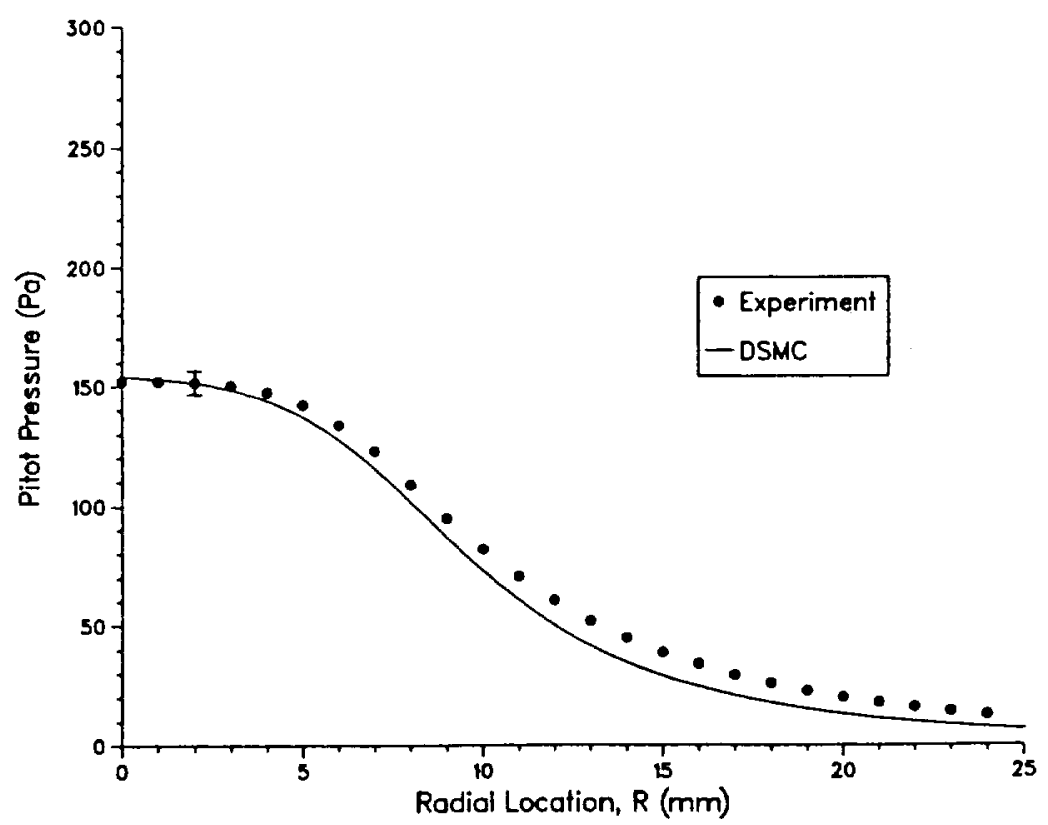

Figure 13. Measured and DSMC Pitot Pressure Profiles for Configuration 2 (Axial Location, $Z=24 \mathrm{~mm}$ ) 


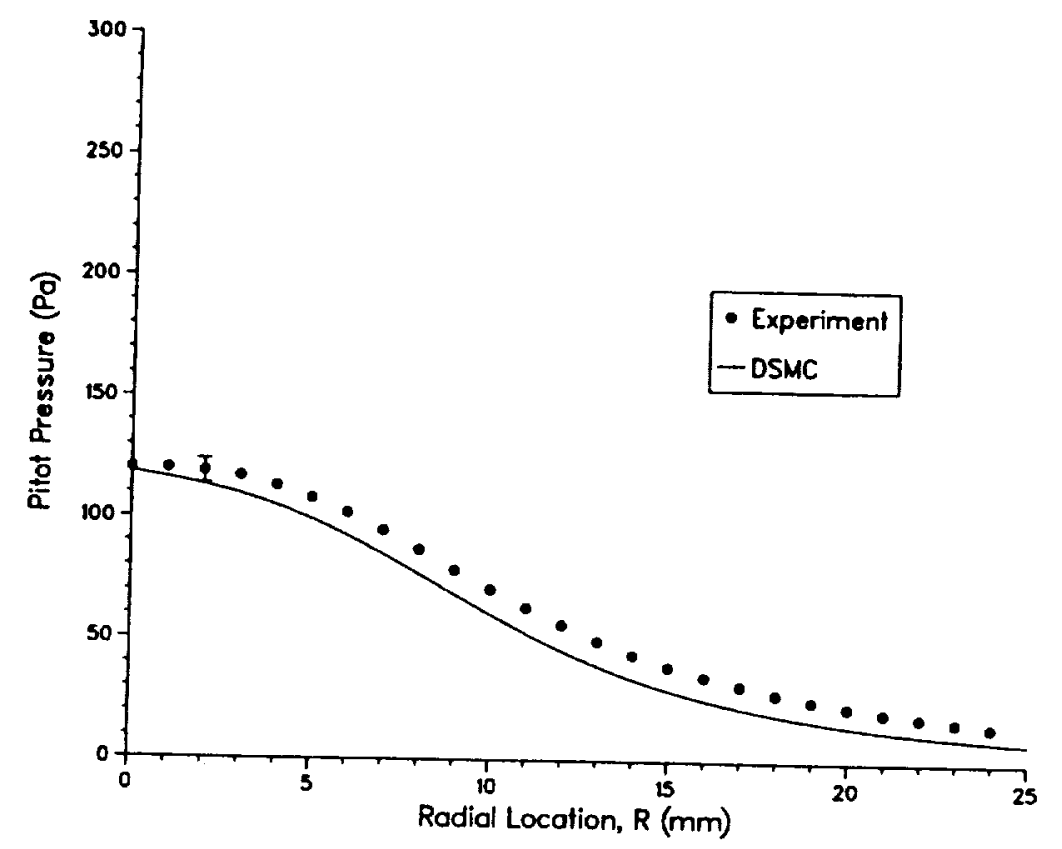

Figure 14. Measured and DSMC Pitot Pressure Profiles for Configuration 2 (Axial Location, $Z=36 \mathrm{~mm}$ )

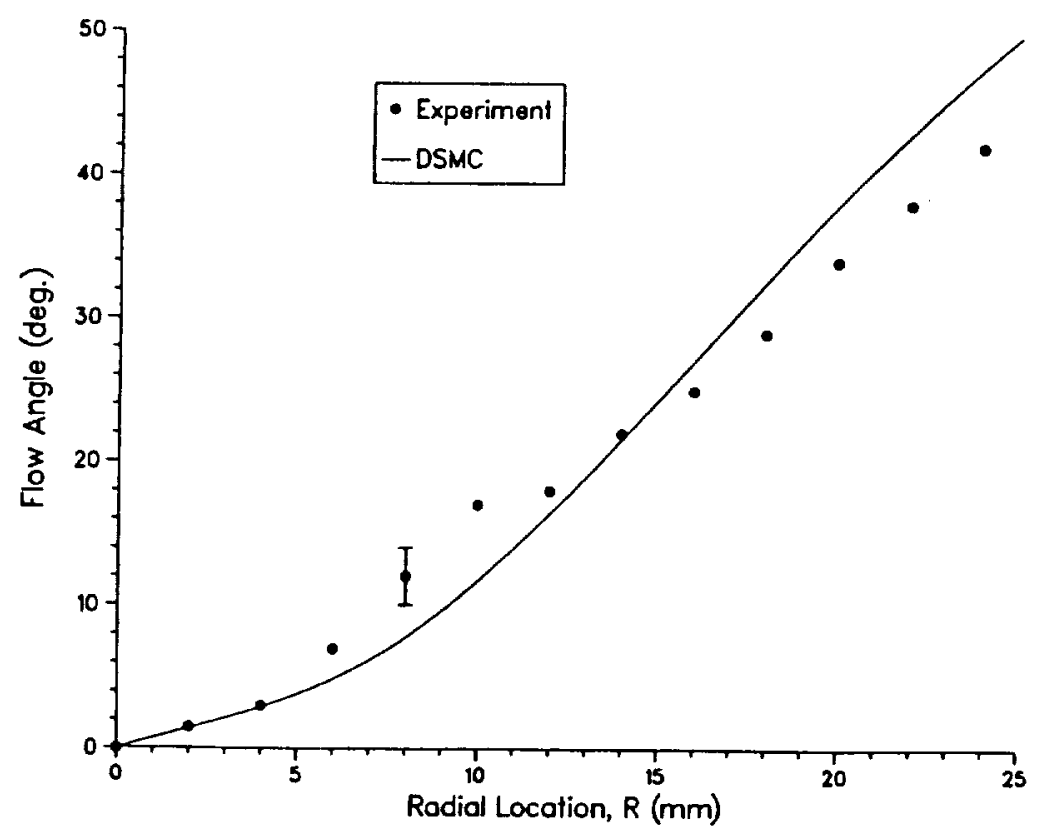

Figure 15. Measured and DSMC Flow Angles for Configuration 2 (Axial Location, $Z=12 \mathrm{~mm}$ ) 
Public reporting burden for this collection of Intormation is estimated to average 1 hour per response, including the time for reviewing instructions, searching existing data sources, Public reporting burden for the data nooded, and completing and reviewing the collection of inlormation. Send comments regarding this burden eatimate or any orther aspect of this gathering and maintaining the data nooded, and completing and reviowing the Washington Hoadquarters Services, Diroctorate for information Operations and Reports, 1215 Jefferson collection of inlos

Davis Highway, Suite 1204, Arlinglon, VA 22202-4302, and to the Ofilo of Management and Budget, Paporwork Roduction Project (0704-018g), Washing

\begin{tabular}{l|l} 
1. AGENCY USE ONLY (Leave blank) & 2. REPORT DATE
\end{tabular}

Technical Memorandum

4. TITLE AND SUBTITLE

Pressure Measurements in a Low-Density Nozzle Plume for Code Verification

6. AUTHOR(S)

Paul F. Penko, Iain D. Boyd, Dana L. Meissner, and Kenneth J. DeWitt
5. FUNDING NUMBERS

WU-506-42-31

8. PERForming organization REPORT NUMBER

E-6463

National Aeronautics and Space Administration

Lewis Research Center

Cleveland, Ohio 44135 - 3191

10. SPONSORING/MONITORING AGENCY REPOAT NUMBER

NASA TM- 105170

AIAA-91-2110

11. SUPPLEMENTARY NOTES Prepared for the 27th Joint Propulsion Conference cosponsored by AIAA, SAE, ASME, and ASEE, Sacramento, California, June 24-27, 1991. Paul F. Penko, NASA Lewis Research Center; Iain D. Boyd, Eloret Institute, NASA Ames Research Center, Moffett Field, California 94035; Dana L. Meissner and Kenneth J. DeWitt, University of Toledo, Toledo, Ohio 43606. Responsible person, Paul F. Penko, (216) 433-2404.

12a. DISTRIBUTION/AVAILABILITY STATEMENT

12b. DISTRIBUTION CODE

Unclassified - Unlimited

Subject Category 20

13. ABSTRACT (Maximum 200 words)

Measurements of Pitot pressure were made in the exit plane and plume of a low-density, nitrogen nozzle flow. Two numerical computer codes were used to analyze the flow, including one based on continuum theory using the explicit MacCormack method, and the other on kinetic theory using the method of direct-simulation Monte Carlo (DSMC). The continuum analysis was carried to the nozzle exit plane and the results were compared to the measurements. The DSMC analysis was extended into the plume of the nozzle flow and the results were compared with measurements at the exit plane and axial stations 12,24 and $36 \mathrm{~mm}$ into the near-field plume. Two experimental apparatus were used that differed in design and gave slightly different profiles of pressure measurements. The DSMC method compared well with the measurements from each apparatus at all axial stations and provided a more accurate prediction of the flow than the continuum method, verifying the validity of DSMC for such calculations.

14. SUBJECT TERMS

Plume measurement; Pitot pressure; Rarefield flow
15. NUMBER OF PAGES

18

16. PRICE CODE

A03

\begin{tabular}{|c|c|c|}
\hline $\begin{array}{c}\text { 17. SECURITY CLASSIFICATION } \\
\text { OF REPORT } \\
\text { Unclassified }\end{array}$ & $\begin{array}{c}\text { 18. SECURITY CLASSIFICATION } \\
\text { OF THIS PAGE } \\
\text { Unclassified }\end{array}$ & $\begin{array}{c}\text { 19. SECURITY CLASSIFICATION } \\
\text { OF AESTRACT }\end{array}$ \\
\hline
\end{tabular}

NSN 7540-01-280-5500

\section{PREGEDING PAGE BLANK NOT FILMED}



National Aeronautics and

Space Administration

Lewis Research Center

Cleveland, Ohio 44135

Official Business

Penalty for Privale Use $\mathbf{3 3 0 0}$

\section{FOURTH CLASS MAIL}

$|\|| \mid$

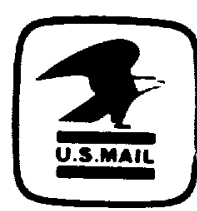

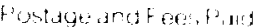
Niatoonal Aeromitutur alad Sipare Adtritudatsicor

$\because A C A A A D$ 